\title{
Numerical modelling of a geothermal pile in tropical environment based on a TRT Test
}

\author{
Caique R. de Almeida ${ }^{1,}$, Maria Eugênia G. Boscov ${ }^{2}$, Cyro Albuquerque Neto ${ }^{3}$ and Cristina de H.C.Tsuha ${ }^{4}$ \\ ${ }^{1}$ Polytechnic School of University of São Paulo, Av. Prof. Luciano Gualberto, 380 - Butantã, São Paulo, SP, Brazil. \\ ${ }^{2}$ Polytechnic School of University of São Paulo, Av. Prof. Luciano Gualberto, 380 - Butantã, SP, Brazil. \\ ${ }^{3}$ FEI University Center, Av. Humberto de Alencar Castelo Branco, 3972, São Bernardo do Campo, SP, Brazil. \\ ${ }^{4}$ Engineering School of São Carlos of University of São Paulo, Av. Trabalhador São Carlense 400, SC, SP, Brazil.
}

\begin{abstract}
The continuous search for sustainable renewable energy sources has motivated the use of geothermal piles to heat or cool buildings, resulting in lower electric energy consumption. Geothermal piles are foundation elements used to provide structural support and thermal comfort. In countries with tropical climate, geothermal piles dissipate heat from the internal environment of the building to the foundation soil. This paper presents a numerical model of a geothermal pile inserted in a saturated sandy soil in São Paulo City, Brazil. The model was developed with ANSYS CFX version 19.2 program, a high performance CFD (Computational Fluid Dynamics) tool. Data from a Thermal Response Test (TRT) carried out for 10 days in the campus of São Paulo University was used to calibrate the model. The development of the model comprised experimental data, geometry, mesh, boundary conditions and simplifying assumptions. The calibration was carried out as back-analysis of experimental data. The obtained numerical results are considerably close to the experimental results, showing that the model is consistent. The validated model will be used to study the influence of geotechnical, hydraulic, thermal, and geometrical parameters on heat transfer, involving water, pipes, concrete and soil.
\end{abstract}

\section{Introduction}

Heating air conditioning with geothermal piles is a technique widely used in European countries, where severe winters make costs with heating mandatory $[1,2]$. Its use grows on average $10 \%$ per year [3]. Figure 1 illustrates a geothermal pile system.

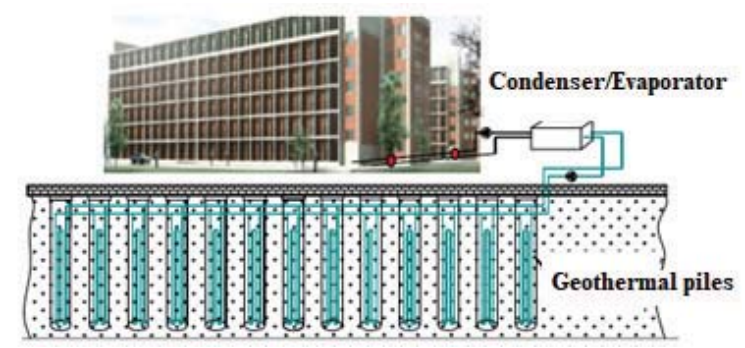

Figure 1. Geothermal pile system [1]

Geothermal piles are double-function foundations as they work as structural support elements and as heat exchangers. A geothermal system or GSHP (Ground Source Heat Pump) consists of three elements: the heat pump, the ground heat exchanger system and the pipe system that transmits cooled or heated fluid to the building. The circulation of a fluid inside a closed circuit of pipes inserted in the pile ensures heat transportation. The GSHP system can be used to cool or heat a building, given that the underground temperature at a certain depth is constant along time.

The main heat transfer mechanisms in problems involving geothermal piles are [4]:

- Convection: is the mode of heat transfer that occurs between a fluid and a surface (solid or other fluid) due to the movement of the fluid itself. The phenomenon involves combined effects of fluid conduction and movement. It is also possible that convection occurs in soils due to moving groundwater, natural convection and vapor diffusion [5];

- Conduction: is the form of heat transfer from particles with higher thermal energy (higher molecular agitation) to particles with lower thermal energy (lower molecular agitation) due to interactions among particles of a substance. Despite being a predominant phenomenon in solids, conduction can also occur in liquids and gases.

The most relevant parameters in heat exchange processes involving geothermal piles are:

- Thermal capacity (c): of a material is defined as its property of storing thermal energy [6]. Thermal capacity relates the amount of heat energy supplied to a body to the temperature alteration it experiences.

- Thermal diffusivity $(\alpha)$ : is described as the ability of a material to conduct heat compared to its capacity to

\footnotetext{
* Corresponding author: crdealme@usp.br
} 
store thermal energy. It may be considered as a representation of how quickly heat diffuses through a material.

- Thermal conductivity $(\mathrm{k})$ : is the heat rate transferred through a unit thickness of a material per unit area and per unit difference of temperature. Therefore, the thermal conductivity of a material reflects its ability to conduct heat. Materials with high thermal conductivity values are referred to as conductors, while low thermal conductivity are thermal insulating materials.

The Thermal Response Test (TRT) is one of the most reliable tools to determine thermal parameters by in-situ testing. TRT consists of applying constant heating power, with the aid of hydraulic and heat pumps, to a fluid circulating in a borehole or in a geothermal pile. Collected inlet and outlet temperature data from the hole/pile are interpreted to provide the desired parameters [7]. Figure 2 illustrates the experiment.

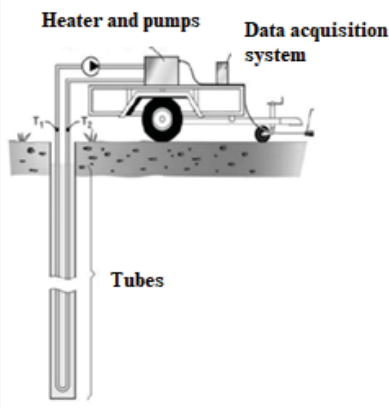

Figure 2. Representation of a TRT Test [7]

Geothermal piles in Brazil are still at research stage, investigations being carried out by numerical simulation and experimental analysis of geothermal piles in unsaturated tropical soils. This paper aims to analyse the thermal behaviour of geothermal piles to be built in saturated sandy subsoil inside the campus of São Paulo University, by numerical modelling and interpretation of a TRT test. The purpose is to validate a numerical model that will be used to a parametric study.

\section{Methodology}

\subsection{TRT Test}

The TRT test was carried out with a geothermal pile (diameter $0.35 \mathrm{~m}$ and length $15 \mathrm{~m}$ ) with a single circuit of U-shaped HDPE pipes ( $32 \mathrm{~mm}$ outer diameter and 26 $\mathrm{mm}$ inner diameter). The soil profile is composed of clayey sand, covered by organic silt-sandy clay $(2.5 \mathrm{~m}$ thick) and, at the top, by a $1 \mathrm{~m}$ layer of red to gray siltysandy clay. The water table was $1.9 \mathrm{~m}$ deep during the test. Figure 3 illustrates the system and soil profile.

The pile was built with 0.55 cement/aggregate and $0.50 \mathrm{cement} /$ water grout. The equipment consisted of a heat reservoir, a circulation pump, a flowmeter, three PT-100 type sensors and a high-resolution data acquisition system. The test duration was 10 days during the Brazilian summer (February 2017).

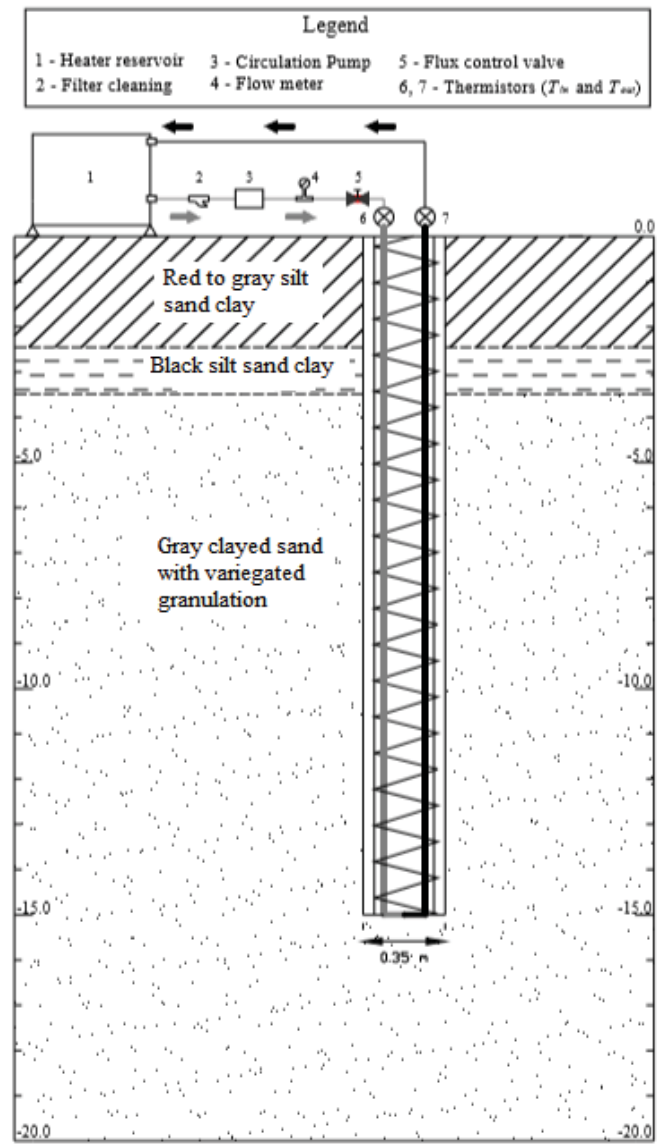

Figure 3. Scheme of TRT Test in the soil profile [8]

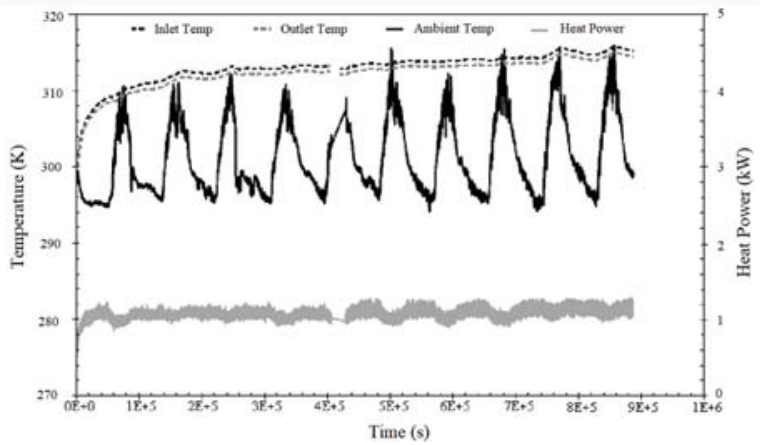

Figure 4. Variation of temperature and heat power in the TRT Test [8]

An electric heat reservoir of $0.1 \mathrm{~m}^{3}$ volume and $1 \mathrm{~kW}$ heating rate was used with water as the circulating fluid. Tubes and sensors were thermally insulated. To determine undisturbed soil temperature a water circulation test was performed. The used flow rate is equal $3.52 .10-3 \mathrm{~m}^{3} / \mathrm{s}$ to ensure turbulent flow. The applied power is equal to $1061 \mathrm{~W}$, or $70.8 \mathrm{~W} / \mathrm{m}$ (heat rate per unit length of pile). The interpretation of results was based on the Kelvin linear heat source theorem. Figure 4 presents the TRT test results. The variation in ambient temperature influences the inlet and outlet temperatures of the circulating fluid. After 50 hours, the geothermal system tends to reach stability. Table 1 summarizes measurements during the test. 
Table 1. TRT Test results. [8]

\begin{tabular}{|c|c|}
\hline TRT measurements & Value \\
\hline Undisturbed ground temperature $(\mathrm{K})$ & 297.33 \\
\hline Average ambient temperature $(\mathrm{K})$ & 301.15 \\
\hline Maximum ambient temperature $(\mathrm{K})$ & 315.95 \\
\hline Minimum ambient temperature $(\mathrm{K})$ & 294.15 \\
\hline $\mathrm{T}_{\text {in }} 50$ hours $(\mathrm{K})$ & 312.45 \\
\hline $\mathrm{T}_{\text {out }} 50$ hours $(\mathrm{K})$ & 311.65 \\
\hline $\mathrm{T}_{\text {in }} 100$ hours $(\mathrm{K})$ & 313.25 \\
\hline $\mathrm{T}_{\text {out }} 100$ hours $(\mathrm{K})$ & 312.45 \\
\hline $\mathrm{T}_{\text {in }} 200$ hours $(\mathrm{K})$ & 314.25 \\
\hline $\mathrm{T}_{\text {out }} 200$ hours $(\mathrm{K})$ & 313.55 \\
\hline Flow rate $(\mathrm{m} / \mathrm{s})$ & 0.66 \\
\hline Average heat power $(\mathrm{kW})$ & 1.06 \\
\hline
\end{tabular}

$\mathrm{T}_{\mathrm{in}}=$ inlet temperature, $\mathrm{T}_{\mathrm{out}}=$ outlet temperature

Table 2 presents values of thermal conductivity and resistance parameters obtained by linear fitting to the curve of variation of average fluid temperature as a function of logarithm of time.

Table 2. Thermal conductivity and thermal resistance. [8]

\begin{tabular}{|c|c|c|c|}
\hline $\boldsymbol{\lambda}$ & $\mathbf{R}^{\mathbf{2}}$ & $\mathbf{k}$ & $\mathbf{R} \mathbf{b}$ \\
\hline- & - & $\mathrm{W} \cdot \mathrm{m}^{-1} \cdot \mathrm{K}^{-1}$ & $\mathrm{~m} \cdot \mathrm{K} \cdot \mathrm{W}^{-1}$ \\
\hline 1,99 & 0,85 & 2,82 & 0,13 \\
\hline
\end{tabular}

$\lambda=$ angular coefficient of the linear regression, $\mathrm{R}^{2}=$ linear regression coefficient, $\mathrm{k}=$ thermal conduticvity of the soil, $\mathrm{R}_{\mathrm{h}}=$ thermal resistance of the pile

\subsection{Numerical model}

The software used in the simulations was ANSYS CFX 19.1. It represents the physical phenomenon of geothermal piles through partial differential equations. In Computational Fluid Dynamics (CFD), the CFX application uses the Finite Volume Method (FVM) as a form of discretization for the equations' solution.

In the Finite Volume Method, the solution domain is divided into a finite number of Control Volumes (CV) and the conservation equations are applied to each Control Volume. At the centroid of each Control Volume there is a node for which the variable values are calculated. At the end, an equation is listed for each Control Volume, as well as the values of the variables at each node and adjacent nodes [9]. The FVM performs a conservation balance for each elementary volume in order to obtain an approximate equation [10].

The conservation equations (also called Navier-Stokes equations) solved numerically by ANSYS are:

- Conservation of mass, expressed by Equation 1;

$$
\partial \rho / \partial \mathrm{t}+\operatorname{div}(\rho . \mathrm{V})=0
$$

- Conservation of momentum between times $t$ and $t+\Delta t$ (for a Control Volume), which maintains the assumptions of Newton's Second Law and is generically presented by Equation 2;

$$
\mathrm{m}_{\mathrm{i}} \mathrm{V}_{\mathrm{i}}(\mathrm{t}+\Delta \mathrm{t})-\mathrm{m}_{\mathrm{i}} \mathrm{V}_{\mathrm{i}}(\mathrm{t})=\Delta(\mathrm{mV})_{\text {system }}
$$

- Conservation of energy, kinetic and internal, for a Control Volume between times $t$ and $t+\Delta t$, by applying the First Law of Thermodynamics, according to Equation 3:

$$
\mathrm{Q}_{\text {in }}-\mathrm{W}_{\text {out }}+\mathrm{E}_{\text {in }}-\mathrm{E}_{\text {out }}=\Delta \mathrm{E} / \Delta \mathrm{t}
$$

where: $\rho$ is the specific mass, $\mathrm{V}$ is the volume of the Control Volume, $\mathrm{m}$ is the mass of the Control Volume and $t$ is the time instant. In addition, $\mathrm{Q}_{\text {in }}$ is the heat flux that enters the system and $\mathrm{W}_{\text {out }}$ is the variation along time of the work performed by the system. The variable E refers to the energy in transit in the Control Volume.

The performed simulations used as input the parameters listed in Table 2 in stationary conditions at times $50 \mathrm{~h}, 100 \mathrm{~h}$ and $200 \mathrm{~h}$.

\subsubsection{Geometry}

The Space Claim module of ANSYS CFX software was used to create the geometry of the numerical model. The pile has a $0.35 \mathrm{~m}$ diameter and $15 \mathrm{~m}$ length. The Ushaped tubes have an inner diameter of $26 \mathrm{~mm}$ and an outer diameter of $32 \mathrm{~mm}$. The U-curve is $10 \mathrm{~cm}$ distant from the underside of the pile. The steel cage was ignored because not relevant in heat exchange processes (in the performed test the steel cage had no structural function), a hypothesis also adopted by [11] and [12].

The soil was modelled as a continuous medium with a cylindrical shape and a radius of $3 \mathrm{~m}$, a distance large enough for the influence of pile heating on the soil to be negligible. The distance from the pile centre from which ground temperatures are equivalent to the undisturbed state was estimated to be $3 \mathrm{~m}$ by [13], $3 \mathrm{~m}$ by [8] and 2.5 $\mathrm{m}$ by [11]. A $3 \mathrm{~m}$ distance below the lower face of the pile was considered. The simulations were performed on a symmetrical half of the problem, aiming to decrease the computational cost. Figure 5 illustrates the geothermal TRT Test's geometry.

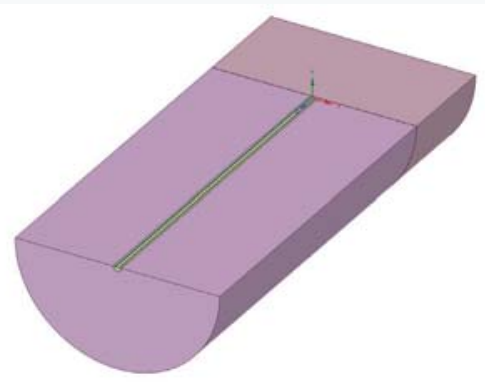

Figure 5. Geometry of the TRT Test

\subsubsection{Mesh}

The mesh was created through the Meshing module, present in the ANSYS CFX software. The mesh was refined in the region where there is circulating fluid, since the phenomena of turbulent water movement and forced convection make modelling more complex. The 
complexity of phenomena makes simplifying hypotheses difficult to apply. Therefore, tetrahedral elements were used for the circulating fluid mesh, which are suitable for complex geometric configurations ("U" curve).

Another advantage of tetrahedral elements is that they make it easier to mesh in transition zones, where hexahedral elements usually have problems. However, the tetrahedral elements of different dimensions from the pile and fluid geometry must be matched to maintain proper mesh connectivity and quality. For this, the inflation command is used, which generates prismian elements to solve connection problems.

The space delimited by the surfaces of the HDPE pipes, through which the fluid circulates, has 258,400 nodes and 551,765 elements. Figure 6 shows the mesh in the region of the "U" curve.

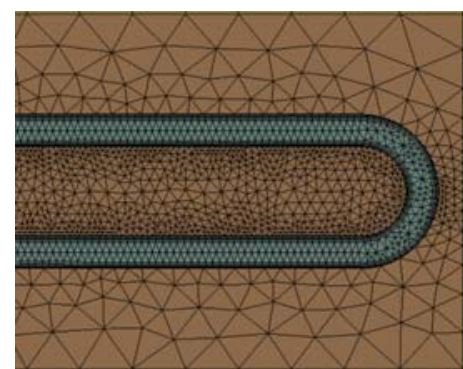

Figure 6. Mesh in the fluid and concrete region

For the modelling of the soil surrounding the pile, hexahedral elements were chosen, because they have the advantage of forming a mesh with fewer elements. As a result, faster computational solutions are obtained. The choice of this type of element is only coherent because the elements are aligned in the direction of the thermal flow and the surrounding geometry is simple. In this geometry, 692,640 nodes and 661,248 elements were employed. Figure 7 illustrates the ground mesh around the pile with respect to the $\mathrm{XY}$ axis.

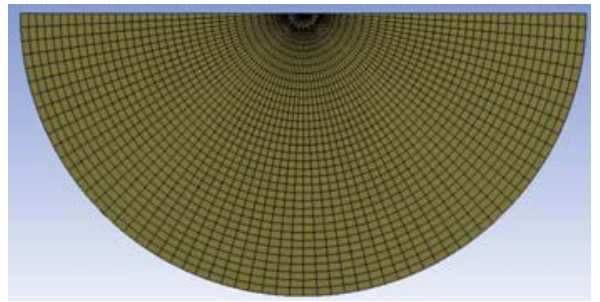

Figure 7. Soil mesh surrounding the geothermal pile

As the surrounding soil mesh approaches the region where water flow phenomena occurs, smaller elements are necessary to guarantee a progressive refinement of the soil to the concrete. Tetrahedral elements were used for the concrete pile as the best configuration to meet the criterium of greater refinement, while it was possible to achieve an adequate transition between the surrounding soil (coarser) and fluid mesh (more refined). The region between the HDPE pipes is now more refined compared to the elements between the ground and the pipe boundaries, since the volume between the pipes is a transition between very refined regions.
For the concrete pile 270,148 nodes and 1349,839 elements were used. Figure 8 illustrates the concrete pile mesh in three-dimensional view.

The ground geometry under the pile demands less refinement because the only phenomenon that occurs is conduction. However, the mesh should match the ground elements surrounding the pile and the concrete pile. Therefore, the best solution for the soil mesh under the pile bottom is to use tetrahedral elements. The soil's geometry under the pile has 50,042 nodes and 260,957 elements.

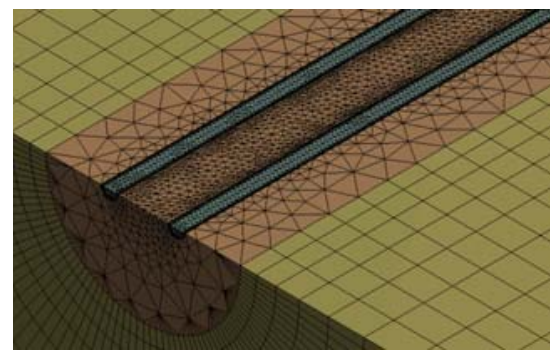

Figure 8. Concrete pile mesh

Figure 9 shows the distribution of tetrahedral elements to the soil at the bottom of the pile.

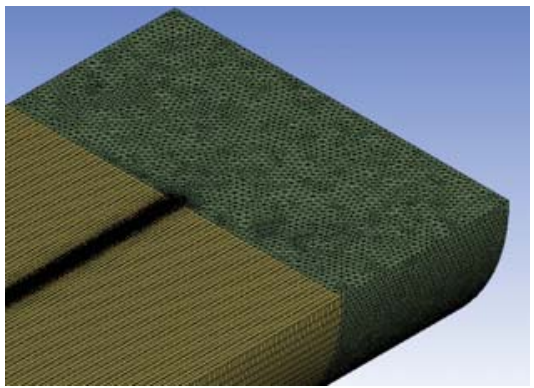

Figure 9. Soil mesh under the pile

\subsubsection{Turbulence model}

The turbulence model used in the Setup module was the $\mathrm{K}$ - epsilon (k-E), commonly used in CFD simulations. This model is based on two equations that represent the turbulent flow properties: the turbulent kinetic energy $\left(\mathrm{k}_{\mathrm{t}}\right)$ and the turbulent energy dissipation $\left(\varepsilon_{\mathrm{t}}\right)$ responsible for determining the turbulence scale.

\subsubsection{Material parameters and boundary conditions}

The behavior of the TRT test performed by [8] in the campus of São Paulo University was simulated to compare the experimental results with those provided by the numerical model. Obtaining adequate results in the calibration phase makes the numerical model reliable for parametric studies.

This paper intends to understand the behavior of the geothermal system at steady state conditions, when the thermal exchanges between fluid, pipes, concrete and soil reached stability conditions. Material parameters and 
boundary conditions are inputs in the Setup module of the ANSYS CFX software.

The values used for the concrete pile according to the TRT test were: density $2400 \mathrm{~kg} / \mathrm{m}^{3}$, specific thermal capacity $1000 \mathrm{~J} / \mathrm{kg} . \mathrm{K}$ and thermal conductivity $2.0 \mathrm{~W}$. $\mathrm{m}^{-1} \cdot \mathrm{K}^{-1}$. The HDPE tubes were simulated by a surface with a thermal resistance of $0.012 \mathrm{~m}^{2} . \mathrm{K} / \mathrm{W}$, calculated from a thickness of $6 \mathrm{~mm}$ and a thermal conductivity of $0.5 \mathrm{~W} \cdot \mathrm{m}^{-1} \cdot \mathrm{K}^{-1}$.

The fluid circulating through the pipes is water, with its properties at $298.15 \mathrm{~K}$ : density $997 \mathrm{~kg} / \mathrm{m}^{3}$, specific thermal capacity $4181.7 \mathrm{~J} / \mathrm{kg} . \mathrm{K}$, thermal conductivity $0.6069 \mathrm{~W} \cdot \mathrm{m}^{-1} \cdot \mathrm{K}^{-1}$. The thermal conductivity of the soil was estimated in the TRT test: $2.82 \mathrm{~W} \cdot \mathrm{m}^{-1} \cdot \mathrm{K}^{-1}$. The soil specific thermal capacity of $1578.9 \mathrm{~K} / \mathrm{kg} . \mathrm{K}$ was estimated based on Lhendup et al. (2014).

Results from three times were simulated, at which the TRT Test was operating under stable conditions. The following boundary conditions were applied:

- Time $\mathrm{t}=50 \mathrm{~h}$ : fluid inlet temperature $312.42 \mathrm{~K}$, mass flow $0.3363 \mathrm{~kg} / \mathrm{s}$, ambient temperature $310.71 \mathrm{~K}$, heating power $1031.20 \mathrm{~W}$, undisturbed ground temperature 297.33 K (same for the three times);

- Time $\mathrm{t}=100 \mathrm{~h}$ : fluid inlet temperature $313.26 \mathrm{~K}$, mass flow $0.3366 \mathrm{~kg} / \mathrm{s}$, ambient temperature $311.16 \mathrm{~K}$, heating power $1083.44 \mathrm{~W}$;

- Time $\mathrm{t}=200 \mathrm{~h}$ : fluid inlet temperature $314.29 \mathrm{~K}$, mass flow rate $0.3663 \mathrm{~kg} / \mathrm{s}$, ambient temperature $313.10 \mathrm{~K}$, heating power $1107.29 \mathrm{~W}$;

At the top of the geothermal system there is heat exchange by natural convection. At the outlet tubes the fluid is assumed to flow at atmospheric pressure. Soil temperature of $297.33 \mathrm{~K}$ was adopted for the distance of $3 \mathrm{~m}$ and at $3 \mathrm{~m}$ below the lower face of the pile. Initially, the pile and soil temperatures are equal. In addition, the soil domain is adiabatic. Water circulates inside turbulent tubes with Reynolds number equal to 17,109 .

\section{Results}

The simulations developed with the parameters and conditions previously presented provided numerical results consistent with the experimental ones, with errors below $0.13 \%$. Table 3 compares the experimental and numerical values of a average circulating fluid outlet temperature at the simulated steady-state times.

Table 3. Comparison of experimental and numerical values of average circulating fluid outlet temperature

\begin{tabular}{|c|c|c|c|}
\hline Time (h) & $\begin{array}{c}\text { Tout }_{\text {- }} \\
\text { Experimental } \\
\text { (K) }\end{array}$ & $\begin{array}{c}\mathbf{T}_{\text {out }}- \\
\text { Numerical } \\
\text { (K) }\end{array}$ & Error (\%) \\
\hline 50 & 311.7 & 312.0 & 0.126 \\
\hline 100 & 313.3 & 312.9 & 0.123 \\
\hline 200 & 314.3 & 313.9 & 0.095 \\
\hline
\end{tabular}

Figure 10 shows the total heat transfer rate values obtained for the simulated times through the interfaces (the soil limit is $3 \mathrm{~m}$ radius away from the center of the pile). As expected, rates at the concrete/soil interface increased from $50 \mathrm{~h}(420.042 \mathrm{~W})$ to $200 \mathrm{~h}(474.632 \mathrm{~W})$, when the geothermal system reaches stable conditions.

Heat transfer rates at the pipe/concrete interface are slightly higher than those at the concrete/ground interface (at time $\mathrm{t}=200 \mathrm{~h}$, heat transfer rate at the pipe/concrete interface is $479.148 \mathrm{~W}$ and at the concrete/ground interface, $474.632 \mathrm{~W})$. The boundary soil surface presents much higher rates $(723.336 \mathrm{~W}$ at time $\mathrm{t}=200 \mathrm{~h}$ ), due to the heat absorbed from the environment above the soil-pile system, where the air temperature is $313.1 \mathrm{~K}$. This hypothesis is supported by the transfer rates of total heat of the top soil interface, which are equivalent to the difference between the pipe/concrete and ground boundary interface rates. For longer times the curves respectivelly reach plateaus.

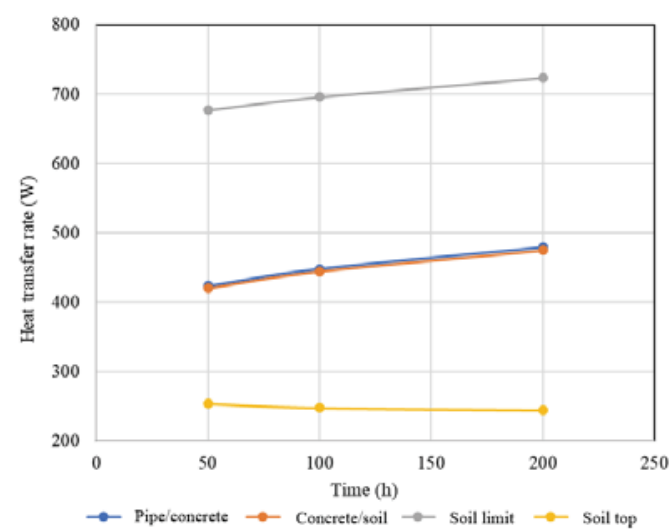

Figure 10. Heat transfer rate through each interface as a function of time

The distribution of average temperatures along time at the geothermal system interfaces is shown in Figure 11. At each interface, temperatures increased slightly from $50 \mathrm{~h}$ to $200 \mathrm{~h}$.

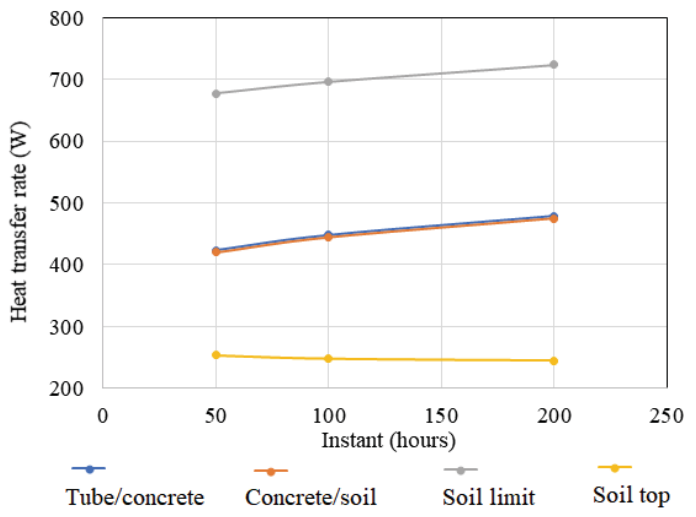

Figure 11. Average temperature variation per interface as a function of time

Figure 12 shows, from a XY plane located at a depth of $7.5 \mathrm{~m}$, the radial distribution of temperatures in the geothermal system at time $\mathrm{t}=200 \mathrm{~h}$. The temperatures 
decrease as the radial distance from the center of the pile increases until, on the ground surface boundary, the average temperature is equal to the undisturbed ground temperature (297.3 K).

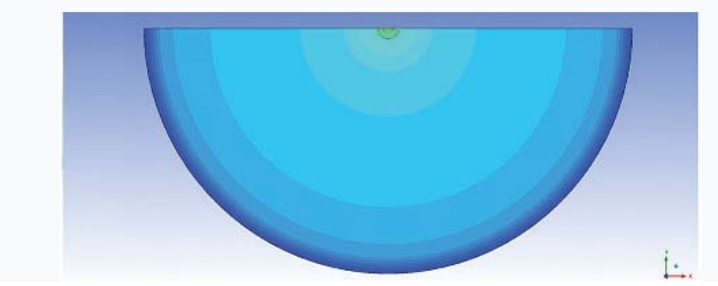

Figure 12. Temperature distribution in the $\mathrm{XY}$ plane and at a depth of $7.5 \mathrm{~m}$ from the geothermal system at time $\mathrm{t}=200 \mathrm{~h}$

Figure 13 illustrates, from the temperature distribution in the $\mathrm{XZ}$ plane (located in the center of the pile), the thermal influence zone at time $\mathrm{t}=200 \mathrm{~h}$, when the thermal influence diameter is $4.55 \mathrm{~m}$.

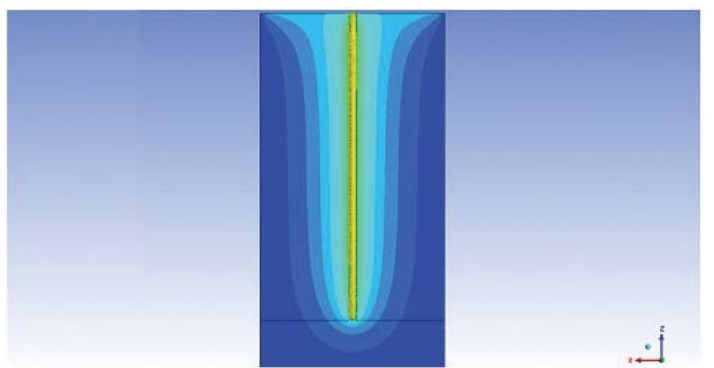

Figure 13. Thermal influence zone at time $\mathrm{t}=200 \mathrm{~h}$

\section{Conclusions}

Simulations for the calibration of the numerical model yielded errors lower than $0.13 \%$ when comparing calculated average circulating fluid outlet temperatures to experimental values. Therefore, the numerical model is considered reliable to perform a parametric study.

The heat transfer rates, the temperatures at each interface and the thermal influence diameters increased from $\mathrm{t}=50 \mathrm{~h}$ to $\mathrm{t}=200 \mathrm{~h}$. At time $\mathrm{t}=200 \mathrm{~h}$ these parameters reached stable values. This behaviour is in accordance with the hypothesis that the geothermal system tends to reach stability after $200 \mathrm{~h}$.

This study shows that numerical models based on Computational Fluid Dynamics can be a reliable tool to obtain results related to geothermal problems. In this research, the elaborated model will be a reference to a parametric study to predict the real scale behaviour of the geothermal piles to be used in the CICS Living Lab.

The authors are thankful to the Coordination for the Improvement of Higher Education Personnel for the financial support and to the University of São Paulo for providing the resources for the research development.

\section{References}

1. Loveridge, F. A.; Powrie, W. Pile heat exchangers: thermal behaviour and interactions. Proceedings of the Institute of Civil Engineers: Geotechnical Engineering, 166(2), [2013].

2. Rotta Loria, A.F.; Gunawan, A.; Shi, C.; Laloui, L.; NG, C. Numerical modelling of energy piles in saturated sand subjected to thermo-mechanical loads. Geomechanics for Energy and the Environment, v.1, 1-15, [2015].

3. Curtis, R.; Lund, J.; Rybach, L.; Hellstrom, G. Ground Source Heat Pumps - Geothermal energy for anyone, anywhere: current worldwide activity. Proceedings World Geothermal Congress, Antalaya, Turquia, 24-29, [2005].

4. Çengel, Y.A. Heat transfer: a practical approach. 2 ed. Nova Iorque, EUA: Mcgraw-Hill, [2003].

5. Baser, T.; Dong, Y; Moradi, A.M.; Lu, N.; Smiths, K.; Ge, S.; Tartakovsky, D.; McCartney, J.S. Role of Nonequilibrium Water Vapor Diffusion in Thermal Energy Storage Systems in the Vadose Zone. Journal of Geotechnical and Geoenvironmental Engineering, v.144, issue 7, [2018].

6. Bergman, T.L.; Lavine, A.S.; Incropera, F.P.; Dewitt, D.P. Introduction to heat transfer. 5 ed. Nova Jersey, EUA: John Wiley \& Sons: [2007].

7. Bandeira Neto, L.A. Estudo experimental da resposta térmica de fundações por estacas trocadoras de calor em solo não saturado. 2015. Dissertation (Masters) - São Paulo University, São Paulo, [2015].

8. Morais, T.S.O.; Tsuha, C.H.C. In-situ measurements of the soil thermal properties for energy foundation applications in São Paulo, Brazil. Bulgarian Chemical Communications, v.50, 34-41, [2018].

9. Gonçalves, N.D.F. Método dos volumes finitos em malhas não-estruturadas. 72 p. Dissertation (Masters) - Porto university, Porto, [2007].

10. Maliska, C.R. Transferência de calor e mecânica dos fluidos computacional. 2 ed. Rio de Janeiro, Brasil: Editora LTC, [2004].

11. Ozudogru, T.Y.; Olgun, C.G. 3D numerical modelling of vertical geothermal heat exchangers. Geothermics, v. 51, 312-324, [2014].

12. You, S.; Cheng, X.; Yu, C.; Dang, Z. Effects of groundwater flow on the transfer performance of energy piles: experimental and numerical analysis. Energy and buildings, v.155, 249-259, [2017].

13. Morais, T.S.O.; Tsuha, C.H.C. Energy pile and ground temperature response to heating test: a case study in Brazil. Bulgarian Chemical Communications, v. 48, 115-119, [2016]. 